\title{
Research on the Correlation between Freight Transportation and National Economic Development
}

\author{
Rui Yang ${ }^{1}$ \\ ${ }^{1}$ School of Economics and Management Beijing Jiaotong University Beijing, China
}

\begin{abstract}
Freight transportation is closely related to economic development. Freight transportation will promote economic development, and economic development will also promote the growth of freight transportation. Therefore, quantitative analysis of the relationship between the two has certain research significance. This article explores the correlation between the two stages and different modes of transportation through coupling analysis, cointegration analysis, and gray correlation analysis based on the data from 1989 to 2018 of freight transportation volume and GDP. The study found that, overall, the growth of freight volume has a certain role in promoting economic growth, and the correlation between different modes of transportation is different. Among them, the correlation between water transportation ${ }^{1}$ and GDP is the strongest, and civil aviation is the weakest. The correlation between highways and GDP is stronger than that of railways, and railway freight transportation still has certain development potential under the conditions of green transportation and the "promoting railway instead of highway transportation" environment and transportation policies. According to the analysis, it is expected that the growth of freight volume will continue to drive economic growth in the future, but different modes of transportation will lead to different functions. Therefore, while continuing to maintain the development momentum of the freight transportation industry, adjusting a more reasonable transportation structure will be more conducive to China's economic development.
\end{abstract}

\section{Introduction}

In September 2019, the Program of Building National Strength in Transportation was proposed, which fully demonstrated the importance of the development of the transportation cause. From the Program of Building National Strength in Transportation, we can see the important ideas of the new era to promote the development of transportation and the important position and huge role of the transportation foundation. Therefore, the transportation industry will play a more important role in the future development.

The transportation industry is an important industry in the development of the national economy and a strong support for the development of the national economy, and freight transportation is an important part of the transportation industry. The development of freight transportation can promote China's economic growth, and the rapid economic development will increase the demand for freight transportation. Therefore, the relationship between freight transportation and economic development has become one of the research hot spots.

The transportation of goods is closely related to economic development, and the transportation volume of goods is also an important measure of macroeconomic development and changes. Premier Keqiang Li used the three indicators of electricity consumption, railway freight volume and loan disbursement, namely the "Keqiang Index" to analyze the economic situation of Liaoning Province at that time. In 2009, the volume of road freight transportation in the "Regional Quarterly GDP Data Review and Evaluation Method (Trial)" issued by the National Bureau of Statistics became the core indicator of the GDP development level of various regions, indicating the close connection between freight transportation and economic development. In 2010, the British "The Economist" used the "Keqiang Index" with rail freight volume to assess China's GDP growth. This shows that the relationship between freight transportation and economic development is close, and the volume of freight transportation has become an important reference indicator for measuring changes in macroeconomic development.

To better analyze the correlation between China's freight transportation and economic development, this article is based on the data of freight transportation and GDP from 1989 to 2018, analyzes the correlation between the two stages and different modes of transportation through coupling analysis, cointegration analysis and gray correlation analysis.

Water transportation includes ocean, coastal and inland river 


\section{Literature review}

Freight transportation is closely related to economic development, and many domestic and foreign scholars have studied it. Since the 1990s, foreign scholars have paid attention to the relationship between freight transportation and economic development. At that time, most scholars' research was based on the relationship of "coupling" and "decoupling". Since the beginning of 1990, the formation of EU economic integration and economic globalization has greatly promoted the growth of freight transportation. The emergence of multinational companies has made the transnational transportation of freight more convenient. Therefore, during this period, the freight transportation of European countries has grown faster. Against this background, the 2001 Transportation White Paper first proposed to study the coupling relationship between transportation and economic growth, and predicted that the development of transportation may always be slower than the speed of economic development. In this context, many scholars have studied the relationship between freight transportation and economic growth.

In terms of the coupling analysis of China's freight transportation and economic growth, Zhijun Zhang and Qingle Zuo used the concepts of coupling in physics to analyze the relationship between road freight transportation and national economic development. The research results show that: in the time dimension, the coupling degree of highway freight volume, highway freight volume, highway freight volume and GDP is relatively high, and the vertical development trend is good; the coupling coordination degree in the spatial dimension is relatively close, and the horizontal difference is obvious[1]. Domestic scholar Minxue Gao, Yukun Li, Jingping Li studied the relationship between China's freight transportation and economic growth from the perspective of coupling and decoupling, and found that the two experienced the evolution process of uncouplingincreasing coupling-coupling-decoupling signs, and proposed that China's transportation system has begun to transform from "scale and speed" to "quality and efficiency"[2]. Zhiguo Jiang analyzed the correlation between comprehensive transportation and freight volume and the national economy. The study found that developed countries'freight transportation has been decoupled from the economy, but for developing countries, the relationship between the two is still relatively close[3].

In terms of the co-integration analysis of China's freight transportation and economic growth, Hao Xiong, Youwang Sun used the data from 1978-2007 as a sample to conduct a co-integration analysis of the freight volume and the volume of freight generation. The research found that there is a long-term equilibrium relationship between the freight volume and the output value of the primary industry and the proportion of the secondary and tertiary industries. There is a long-term equilibrium relationship between production volume and GDP and the proportion of primary industry[4]. Xiao Liang, Chunping Hu, Kun Qian, Baohua Mao constructed a linear regression model between freight turnover and GDP, and analyzed its periodic characteristics, and found that there is a linear relationship between the two, and with economic development, the turnover of goods required for the growth of unit GDP gradually decreases[5]. Yuchu Zhou, Xuhong Wen, Shijun Zhang studied the co-integration relationship between freight turnover and GDP for different modes of transportation, and found that there is a unique co-integration relationship between the national economy and railway, highway, and water transportation turnover. Among them, the railway has the greatest effect on the national economy[6].

In terms of the grey correlation analysis of China's freight transportation and economic growth, Yongjie Zhang predicted the road freight volume and freight turnover based on the grey system. The main research significance is that it can overcome the discreteness of the original data and construct a high-precision prediction model[7]. Luqing Rong took Guangxi as an example to study the development of regional waterway freight transportation based on gray correlation analysis. By building a metabolic model, etc., it is possible to effectively predict the volume of water freight transportation, and find that the development of industry has the most significant impact on the development of water freight transportation[8]. Huaixin Zhao et al. analyzed the interaction between macroeconomic factors of the national economy and road freight volume and freight turnover, and calculated the degree of influence of economic indicators on road freight volume and freight turnover based on the grey correlation analysis. After the study, it was found that for economic indicators, road freight volume and freight turnover volume showed a similar correlation trend[9].

To sum up, the existing research shows that freight transportation has a certain leading role in economic development. By combing the existing literature, we can find that for the study of the correlation between the two, most scholars use coupled analysis, and there are few analyses on the correlation between different modes of transportation and economic development. Therefore, based on existing theories, through coupling analysis, cointegration analysis and grey correlation analysis, this paper makes a comprehensive analysis of the correlation between the two at different stages and the correlation between different modes of transportation and economic development, and puts forward corresponding suggestions.

\section{Empirical analysis}

This part mainly conducts an empirical analysis of the relationship between freight volume and GDP through coupling analysis, cointegration analysis and gray correlation analysis.

\subsection{Data Sources}

The data in this article are all from the "China Statistical Yearbook", which selects the GDP from 1989 to 2018 and the freight volume of different freight transportation methods to analyze the relationship between freight transportation and economic development. The GDP was adjusted at a constant price in 1978. 


\subsection{Coupling analysis}

Coupling refers to the phenomenon that two or more systems or two forms of motion interact with each other and even unite through interaction. It was originally a concept in mathematics and physics. Coupling relationship means that there is an interaction and mutual influence between two things, and decoupling is just the opposite. It can now be further used to describe the evolution of the relationship between the two phenomena, that is, coupling is the relationship between the two that affects each other, and gradually tends to be consistent. Decoupling means that the relationship between the two is gradually decoupled, and the effect becomes weaker.

Transportation intensity refers to the transportation volume required for each production unit of GDP, that is, the ratio of freight volume to GDP. According to relevant references, this paper uses the growth rate of transport intensity to measure the decoupling or coupling relationship. A positive growth rate indicates that the growth of freight volume is faster than that of

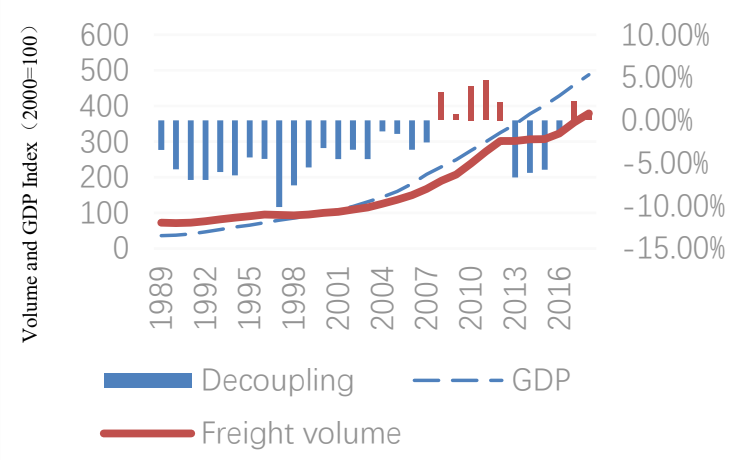

Fig 1. 1989-2018 GDP and freight volume coupling diagram

GDP, and a negative growth rate indicates that the growth of GDP is faster than that of freight volume.

This article selects 1989-2018 GDP and freight volume data to analyze the coupling relationship between the two. Among them, 2000 is used as the standard data of 100, and all data is processed to better measure the coupling relationship between the two.

As shown in Fig. 1, between 1989 and 2018, both GDP and freight volume showed a clear upward trend. The development trends of the two are generally consistent, and there is no obvious decoupling phenomenon while growing. On the whole, freight volume has increased, and GDP has also increased year by year, but the growth of freight volume has been slower than that of GDP. The growth of freight volume during 2008-2012 and 20172018 is faster than that of GDP. It may be because the period of 2008-2012 was the period of the Asian financial crisis. After 2017, it was affected by the global economic crisis and at this time China was in the stage of the new economic normal and supply-side reform, which led to a faster growth in freight volume and a relatively slower GDP growth.

\subsection{Cointegration analysis}

Cointegration test is to check whether there is a long-term stable equilibrium relationship between the explanatory variables and the explained variables. This article uses the EG two-step method to test through the Eviews software to determine whether there is cointegration between the variables. In this paper, through the ADF test, we can find that all sequences are stationary and can be cointegrated. To measure the change rate of the explained variable caused by the percentage change of the explanatory variable, $\log$ the variable, and the regression equation is as follows:

$$
\ln G D P=1.42 \ln H Y L-5.42
$$

As shown in TAB. 1, the residuals are obtained after the initial regression analysis of the indicators, and the ADF test is performed on the residuals. It can be found that the original sequence of the residual sequence is stable, indicating that there is cointegration between the two indicators of GDP and freight volume. The relationship has a long-term stable and balanced relationship, and for every 1 percentage point increase in

Table1. Test results of cointegration relationship between GDP and freight volume

\begin{tabular}{|c|c|c|c|c|}
\hline \multirow{2}{*}{ Residual } & \multicolumn{4}{|c|}{ Residual Test Result } \\
\cline { 2 - 5 } & $\begin{array}{c}\boldsymbol{A D F} \\
\text { statistics }\end{array}$ & $\begin{array}{c}\mathbf{5 \%} \text { critical } \\
\text { value }\end{array}$ & $\begin{array}{c}\boldsymbol{P} \\
\text { value }\end{array}$ & $\begin{array}{c}\text { Test } \\
\text { result }\end{array}$ \\
\hline$\varepsilon$ & -3.061 & -2.998 & 0.044 & stable \\
\hline
\end{tabular}

freight volume, economic growth increases by 1.42 percentage points.

\subsection{Granger causality test}

Granger causality test is a method used to analyze the causality between variables, and it is an effective explanation for the change of another variable caused by the previous change of one variable. The Granger causality test requires a regression, which requires that the time series variables are stationary to avoid false regression. In this paper, there is a long-term equilibrium relationship between the GDP and HYL variables. Granger causality test is performed on these two variables, and the results are shown in TAB. 2.

It can be seen from TAB. 2 that GDP is not the Granger cause of HYL, and HYL is the Granger cause of GDP. This shows that GDP growth can be explained by changes in HYL.

\subsection{Grey Relational Analysis}

Grey relational analysis is an important part of grey theory. Grey relational analysis method is a method to analyze the degree of relation of factors in the system, mainly to quantitatively analyze the degree of relation between factors with grey relational degree. There are four specific steps in grey correlation analysis: determining the analysis sequence, dimensionless processing, calculating grey correlation coefficient, and grey correlation degree. The grey correlation degree refers to the degree of fitting of the development trend between the two factors. The greater 
the correlation degree, the stronger the correlation between the two factors, and the weaker the converse. Therefore, this method can analyze the correlation between different modes of transportation and GDP, and explore the correlation between different modes of transportation and GDP.

Based on the above analysis of grey correlation, this paper calculates the correlation between different freight transportation methods and GDP from 1989 to 2018. The calculation results are shown in TAB. 3 .

It can be seen from the results in TAB. 3 that there are strong correlations between different freight transportation methods and GDP. The correlation degree of various transportation modes is strong to weak, followed by water transportation, highway, pipeline, railway and civil aviation. Among them, water transportation has the highest correlation degree, while civil aviation has the weakest correlation degree.

\begin{tabular}{|c|c|c|c|c|}
\multicolumn{1}{|c}{ Table2. } & \multicolumn{4}{c|}{ Granger test result table } \\
\hline \multirow{2}{*}{ Null Hypothesis } & $\begin{array}{c}\text { Lag } \\
\text { order }\end{array}$ & $\begin{array}{c}\boldsymbol{F} \\
\text { value }\end{array}$ & $\begin{array}{c}\boldsymbol{P} \\
\text { value }\end{array}$ & Conclusion \\
\cline { 2 - 5 } & 4 & 2.338 & 0.097 & accept \\
\hline $\begin{array}{c}\text { GDP } \text { is not a } \\
\text { Granger cause of } \\
\text { HYL }\end{array}$ & 4 & 4.653 & 0.010 & refuse \\
\hline $\begin{array}{c}\text { HYL is not a } \\
\text { Granger cause of } \\
\text { GDP }\end{array}$ & 4 & & \\
\hline
\end{tabular}

\begin{tabular}{|c|c|c|c|c|c|}
\multicolumn{1}{c|}{ Table3. } & \multicolumn{5}{c|}{ Mrey correlation table of different freight modes } \\
\hline \multirow{2}{*}{$\begin{array}{c}\text { Calculatio } \\
\text { n Results }\end{array}$} & $\begin{array}{c}\text { Railwa } \\
\boldsymbol{y}\end{array}$ & $\begin{array}{c}\text { Highwa } \\
\boldsymbol{y}\end{array}$ & $\begin{array}{c}\text { Water } \\
\text { transpo } \\
\boldsymbol{r t}\end{array}$ & $\begin{array}{c}\text { Civil } \\
\text { aviatio } \\
\boldsymbol{n}\end{array}$ & $\begin{array}{c}\text { Pipelin } \\
\boldsymbol{e}\end{array}$ \\
\hline correlation & 0.678 & 0.709 & 0.750 & 0.593 & 0.700 \\
\hline result & \multicolumn{6}{|c|}{ water transport>highway>pipeline>railway>civil } \\
aviation
\end{tabular}

\section{4 conclusion}

In this paper, through reading relevant literature, based on the relevant data of China's freight volume and GDP from 1989 to 2018, a brief description and analysis of the current situation of China's freight transportation and economic growth, and through the coupling analysis, cointegration analysis and gray correlation analysis method to quantitatively study the relationship between the two. The specific conclusions are as follows:

There is a cointegration relationship between GDP and freight volume, and the growth of freight volume has a leading role in economic growth. For every 1 percentage point increase in freight volume, economic growth increased by 1.42 percentage points.

Different freight transportation methods have a strong correlation with GDP, of which water transportation has the highest correlation, while civil aviation has the weakest correlation. This may be due to the important role of water transportation in the transportation of bulk cargoes with large volumes and long distances. With the rapid growth of China's economy, the role of water transportation in ensuring economic growth is becoming more and more obvious. The development of civil aviation will be affected by national strategies and government regulations. When economic growth slows, the development of civil aviation will also show a corresponding trend, and its role in promoting the economy is weak.

The connection of highways is stronger than that of railways, because highway transportation is more flexible and faster than railways, and can meet people's demand for immediate delivery. The development of highway networks is also faster than the development of railway networks. The correlation of GDP is stronger than that of railways.

There is still some room for the development of railway transportation. Under the new situation that China is vigorously promoting the "promoting railway instead of highway transportation", it is necessary to make preparations for improving transportation capacity. Compared with highways, railways are more in line with the concept of green development, with fewer pollutants and lower energy consumption. Facing the adjustment of the transportation structure, that is, reducing the volume of road freight and increasing the volume of railway freight, the railway should continue to deepen the reform of the transportation supply side structure, further optimize the transportation product structure, and make preparations to meet transportation needs and improve service levels.

In summary, the development of freight transportation has a certain role in driving economic growth. Therefore, continuing to maintain the development momentum of the freight transportation industry and adjusting a more reasonable transportation structure will be more conducive to China's economic growth.

\section{Acknowledgment}

I would like to express my gratitude to all those who helped me in the process of writing the thesis. Thanks to my tutor Professor Jianhong Wu for his help, and for his encouragement and professional guidance during my thesis writing. At the same time, I would also like to thank my family, classmates and friends for their help, because they have been helping, supporting and caring for me.

\section{References}

1. Zhijun Zhang, Qingle Zuo. Analysis of coupling coordination degree of highway cargo transportation volume and GDP[J]. Statistics and Decision, 2016(22):92-94.

2. Minxue Gao, Yukun Li, Jingping Li. Research on the relationship between China's freight transportation and economic growth from the perspective of coupling and decoupling[J]. Economic Theory and Economic Management, 2019(05): 75-87.

3. Zhiguo Jiang. Research on the relationship between comprehensive transportation freight volume and national economic development[D]. Southwest Jiaotong University, 2019.

4. Hao Xiong, Youwang Sun. A Co-integration Analysis of the Relationship between China's Freight Volume and Economic Growth[J]. Systems Engineering, 2010, 28(09): 46-50. 
5. Xiao Liang, Chunping Hu, Kun Qian, Baohua Mao. Research on the relationship between cargo turnover and economic development [J]. Logistics Technology, 2011, 30(11): 49-53.

6. Yuchu Zhou, Xuhong Wen, Shijun Zhang. Analysis of the co-integration relationship between freight turnover and GDP of different modes of transportation [J]. Railway Freight, 2017, 35(10): 15$19+24$.

7. Yongjie Zhang. Application of Grey System Theory in Forecasting Road Freight Volume and Freight Turnover Volume [J]. Transportation System Engineering and Information, 2003(01): 75-79.

8. Luqing Rong. Research on the development of regional waterway freight transportation based on ash prediction and ash correlation-taking Guangxi as an example[J]. Journal of Beijing Jiaotong University (Social Science Edition), 2018, 17(02): 109-117.

9. Huaixin Zhao, Xingxing Sun,Qianqian Xu, Yuanjiao $\mathrm{Hu}$,Chaoyun Sun, Wei Li. Correlation factors analysis of highway freight volume and cargo turnover based on gray entropy method[J]. Journal of Transportation Engineering, 2018, 18(04): 160-170.

10. Rong Zhang, Yulu He. Analysis on the influencing factors of China's railway freight volume[J]. Railway Freight, 2019, 37(11): 14-21.

11. Hui Liu. Research on the dynamic relationship between "Keqiang Index" and economic growth-an empirical analysis based on VAR and VEC models [J] Business Times, 2014(01): 11-13.

12. Zhaoyu $\mathrm{Yu}$, Cheng Zhang,Zhijian Zhang. Cointegration Research on the Relationship between Railway Freight Volume and Gross National Economy [J]. Railway Transport and Economy, 2011, 33(12): 1-4. 